\title{
Enhanced mechanical properties in oxide-dispersion- strengthened alloys achieved via interface segregation of cation dopants
}

\author{
Zhi Dong, Zongqing Ma ${ }^{*}$, Liming Yu and Yongchang Liu
}

\begin{abstract}
With significantly enhanced irradiation resistance, high-temperature strength, and creep resistance, oxide-dispersion-strengthened tungsten (ODS-W) alloys present tremendous potential for high-temperature applications. However, the oxide particles tend to segregate at $\mathrm{W}$ grain boundary and grow up (even to micron), greatly suppressing their strengthening effect. It is always a great challenge to effectively refine and disperse the oxide particles at $\mathrm{W}$ grain boundary. Here, we successfully developed a new type of cation-doped $\mathrm{W}-\mathrm{Y}_{2} \mathrm{O}_{3}$ alloy via a wet chemical method and subsequent low-temperature sintering. It was found that proper cation doping could not only significantly refine the intergranular $\mathrm{Y}_{2} \mathrm{O}_{3}$ second phase particles but also dramatically improve the sinterability of $\mathrm{W}$ matrix. These doping effects, as a result, simultaneously enhance the strength and ductility of the $\mathrm{W}-\mathrm{Y}_{2} \mathrm{O}_{3}$ alloy. It was confirmed that the segregation of cation dopants at the $\mathrm{W} / \mathrm{Y}_{2} \mathrm{O}_{3}$ interface is the origin of these doping effects. Furthermore, $\mathrm{X}$-ray photoemission spectra (XPS) analyses confirmed that cation dopant segregation also obviously affects the chemical bonding (i.e., $\mathrm{W}-\mathrm{O}$ bond) along the $\mathrm{W} / \mathrm{Y}_{2} \mathrm{O}_{3}$ interface. As a result, the ratelimiting mechanism for $\mathrm{W}$ grain growth is influenced remarkably, explaining well the difference of $\mathrm{W}$ grain size in various cation-doped $\mathrm{W}-\mathrm{Y}_{2} \mathrm{O}_{3}$ alloys. For the refinement of intergranular $\mathrm{Y}_{2} \mathrm{O}_{3}$ particles, it can be understood well from both thermodynamic and kinetic views. Detailedly, $\mathrm{W} / \mathrm{Y}_{2} \mathrm{O}_{3}$ interfacial energy and atom mobility for $\mathrm{Y}_{2} \mathrm{O}_{3}$ coarsening are all limited by cation dopant segregation. More importantly, this cation-doping approach can also be applicable to other ODS alloys for enhancing their comprehensive mechanical properties.
\end{abstract}

Keywords: oxide-dispersion-strengthened alloys, cation doping, interfacial segregation, strengthening-toughening

\section{INTRODUCTION}

Oxide-dispersion-strengthened (ODS) alloys exhibit remarkably enhanced high-temperature strength and creep resistance compared with their base materials, making them very attractive for applications in various fields such as aerospace [1,2], nuclear [3] and military industry [4]. Especially, for fusion application, the demanding work environment, including high-energy particle irradiation, high temperature field, high stress field and hydrogen retention, put forward a higher quality requirement for material selection [5]. Recently, ODS tungsten (ODS-W) alloys are considered as the most promising candidate for plasma facing materials (PFMs) due to their outstanding microstructural and mechanical stability, especially at high temperatures [3,6]. Generally, the intergranular oxide second phase particles can effectively pin grain boundary of $\mathrm{W}$ matrix, which is beneficial to the hightemperature microstructural stability of ODS-W alloys and then raises their recrystallization temperature [7]. The intragranular oxide particles, on the other hand, can inhibit the movement of dislocation through dispersion/ dislocation interaction, contributing to the promotion of work hardening capacity of $\mathrm{W}$ matrix [8-10]. What is more notable is the abundant phase interface introduced by second phase particle in ODS-W alloys. Radiation defects can be absorbed and dispersed by these phase interface, which inhibits the presence of $\mathrm{H} / \mathrm{He}$ bubbles in $\mathrm{W}$ alloys and then improves their radiation resistance $[11,12]$. In addition, the structural materials in future fission and fusion reactors are also challenges because of their high level of neutron displacement damage and high operating temperatures $\left(500-1000^{\circ} \mathrm{C}\right)$ [13]. Fortunately, the high-temperature creep and tolerance to radiation damage of steels can be improved greatly by dispersing

State Key Lab of Hydraulic Engineering Simulation and Safety, School of Materials Science and Engineering, Tianjin University, Tianjin 300072, China

* Corresponding author (email: mzq0320@163.com) 
ultrafine oxide particles [14]. Due to these characteristics of ODS steels, they have been widely used as the candidate materials in fission and fusion applications.

Recently, the composite powder precursors for sintering ODS alloys were generally prepared by mechanical alloying or the wet chemical method [15-18]. For ODS steels, mechanical alloying is the most successful technology $[19,20]$. Combining mechanical alloying with hot isostatic pressing (HIP), commercial ODS steels on the $1000 \mathrm{~kg}$ scale with remarkably enhanced creep strength has been fabricated. In order to further improve the hightemperature performance of ODS steels, some important parameters such as impurity contents, microstructural refinement of matrix and homogeneous distribution of oxide particles should be controlled carefully. For the preparation of refractory metal alloys such as ODS-W and ODS-Mo, mechanical alloying and the wet chemical method are usually adopted. By sintering the powder precursor produced by mechanical alloying, Xie et al. [21] prepared a W-1\% $\mathrm{Y}_{2} \mathrm{O}_{3}$ alloy. After ensuing rolling, refined equiaxed subgrains are full in elongated mother grains. This special microstructure not only weakens the anisotropy of the rolled plate but also is conductive to the simultaneous enhancement of ductility and strength. However, most of $\mathrm{Y}_{2} \mathrm{O}_{3}$ second phase particles with a size from 500 to $1000 \mathrm{~nm}$ are distributed at the grain boundary, and some are even larger than $1 \mu \mathrm{m}$ [21]. For the wet chemical method, the uniform distribution of oxide second phase particles in composite powder can be controlled easily $[22,23]$. The refined alloy matrix particles possess tremendous driving force for rapid densification at lower sintering temperatures [24,25]. Nevertheless, after sintering of a $\mathrm{Mo}-\mathrm{La}_{2} \mathrm{O}_{3}$ composite powder produced by liquid-liquid doping method, largesized $\mathrm{La}_{2} \mathrm{O}_{3}$ particles $(300-900 \mathrm{~nm}$ ) still exist at Mo grain boundaries although the volume fraction of intragranular $\mathrm{La}_{2} \mathrm{O}_{3}$ particles is increased significantly [9]. Owing to deformation incompatibility, especially for the case of the larger intergranular oxide particles, severe stress concentration could be introduced at these particles easily, resulting in interfacial decohesion or particle cracking and eventual crack initiation along the grain boundary $[9,10,26,27]$. Consequently, the improvement effect of oxide second phase particle addition on the mechanical properties of alloy matrix is depressed greatly. Nowadays, it is urgent and still a great challenge to efficiently refine and disperse the oxide second phase particles within alloy matrix for achieving ODS alloys with excellent mechanical properties.

In this work, with the aim of refining intergranular
$\mathrm{Y}_{2} \mathrm{O}_{3}$ particles and further improving the mechanical properties of $\mathrm{Y}_{2} \mathrm{O}_{3}$ dispersion-strengthened $\mathrm{W}$ alloy, a new type of cation-doped $\mathrm{W}-\mathrm{Y}_{2} \mathrm{O}_{3}$ composite powder precursor was successfully fabricated by the wet chemical method. After low-temperature sintering of this composite powder precursor, it was found that proper cation doping could not only significantly refine and disperse the intergranular $\mathrm{Y}_{2} \mathrm{O}_{3}$ second phase particles, but also dramatically improve the sinterability of $\mathrm{W}$ matrix. As a result, both the strength and ductility of the $\mathrm{W}-\mathrm{Y}_{2} \mathrm{O}_{3}$ alloy are improved remarkably after cation doping, especially for $\mathrm{La}^{3+}$ doping. Through carefully characterizing, it was confirmed that the cation dopant segregation at the $\mathrm{W} /$ $\mathrm{Y}_{2} \mathrm{O}_{3}$ interface is the origin of these doping effects. Furthermore, the effect mechanism of cation dopant segregation on the sinterability of $\mathrm{W}$ matrix and the refinement of intergranular $\mathrm{Y}_{2} \mathrm{O}_{3}$ particles were also discussed.

\section{EXPERIMENTAL SECTION}

\section{Powder synthesis and reduction}

$\mathrm{W}-2 \mathrm{vol} \% \quad \mathrm{Y}_{2} \mathrm{O}_{3}$ and the cation-doped $\mathrm{W}-2 \mathrm{vol} \% \quad \mathrm{Y}_{2} \mathrm{O}_{3}$ composite nanopowder precursors were synthesized through a traditional co-deposited wet chemical method. The cation dopants used here include $\mathrm{Sc}^{3+}, \mathrm{La}^{3+}, \mathrm{Ti}^{4+}, \mathrm{Zr}^{4+}$ and $\mathrm{Hf}^{4+}$. The contents of cation dopants in $\mathrm{W}-\mathrm{Y}_{2} \mathrm{O}_{3}$ composite powder were determined by the volume fraction of corresponding ionic oxides. For example, the nominal composition of the $\mathrm{Sc}^{3+}$-doped $\mathrm{W}-\mathrm{Y}_{2} \mathrm{O}_{3}$ composite nanopowder precursors was $\mathrm{W}-2 \mathrm{vol} \% \mathrm{Y}_{2} \mathrm{O}_{3}$ $0.4 \mathrm{vol} \% \mathrm{Sc}_{2} \mathrm{O}_{3}$. The volume fraction of other ionic oxides including $\mathrm{La}_{2} \mathrm{O}_{3}, \mathrm{TiO}_{2}, \mathrm{ZrO}_{2}$ and $\mathrm{HfO}_{2}$ corresponding to cation dopants all had the same volume fraction with $\mathrm{Sc}_{2} \mathrm{O}_{3}$.

$\left(\mathrm{NH}_{4}\right)_{10}\left[\mathrm{H}_{2} \mathrm{~W}_{12} \mathrm{O}_{42}\right] \cdot 4 \mathrm{H}_{2} \mathrm{O}$ (APT, 99.95\%, Aladdin) and $\mathrm{Y}\left(\mathrm{NO}_{3}\right)_{3} \cdot 6 \mathrm{H}_{2} \mathrm{O}(99.99 \%$, Aladdin) were used as raw materials, and the corresponding dopant sources were $\mathrm{Sc}\left(\mathrm{NO}_{3}\right)_{3} \cdot 6 \mathrm{H}_{2} \mathrm{O} \quad$ (99.99\%, Aladdin), $\mathrm{La}\left(\mathrm{NO}_{3}\right)_{3} \cdot 6 \mathrm{H}_{2} \mathrm{O}$ (99.99\%, Aladdin), $\mathrm{TiCl}_{4}$ (99.99\%, Aladdin), $\mathrm{ZrOCl}_{2}$. $8 \mathrm{H}_{2} \mathrm{O}\left(99.9 \%\right.$, Aladdin) and $\mathrm{HfOCl}_{2} \cdot 8 \mathrm{H}_{2} \mathrm{O}(99.99 \%$, Aldrich). Firstly, a certain amount of $\mathrm{Y}\left(\mathrm{NO}_{3}\right)_{3} \cdot 6 \mathrm{H}_{2} \mathrm{O}$ and dopant sources were dissolved into distilled water where nitric acid $(65 \%-68 \%)$ was added to suppress the hydrolysis of dopant cations. After complete dissolution, $\left(\mathrm{NH}_{4}\right)_{10}\left[\mathrm{H}_{2} \mathrm{~W}_{12} \mathrm{O}_{42}\right] \cdot 4 \mathrm{H}_{2} \mathrm{O}$ was added into the solution and the codeposition reaction was initiated. About 30 min later, in order to restrain the further growth of tungsten oxide hydrate particles, anhydrous ethanol was added into the formed suspension. Then the suspension 
was left to react continuously for another $3 \mathrm{~h}$, followed by collecting the precipitation via filtration. The obtained precipitate was washed with water for three times and then kept in vacuum drying oven at $60^{\circ} \mathrm{C}$ for $24 \mathrm{~h}$. The detailed synthesis process can be found in our previous work $[28,29]$.

The subsequent thermal processes including calcination and reduction, were carried out in a tube furnace. In flowing argon atmosphere, the as-obtained codeposited powders were calcined at $450^{\circ} \mathrm{C}$ for $1 \mathrm{~h}$ firstly. After that, the atmosphere was changed into hydrogen and the temperature was raised to $600^{\circ} \mathrm{C}$ to reduce the composite oxide powders. About $3 \mathrm{~h}$ later, the temperature was increased to $800^{\circ} \mathrm{C}$ and then kept for $6 \mathrm{~h}$. Finally, the reduced powders were cooled to room temperature in flowing hydrogen atmosphere and stored in argon glove box for later use.

\section{Low-temperature sintering}

The reduced powders were firstly pressed into raw compacts with a diameter of $10 \mathrm{~mm}$ and a height of $12 \mathrm{~mm}$ using cold isostatic pressing. Then these pressed compacts were sintered in a box furnace under hydrogen atmosphere. The temperature was gradually increased to $1600^{\circ} \mathrm{C}$ with a heating rate of $5^{\circ} \mathrm{C} \mathrm{min}^{-1}$ and the holding time at $1600^{\circ} \mathrm{C}$ was $4 \mathrm{~h}$. The gas flow rate was maintained at around $500 \mathrm{~mL} \mathrm{~min}^{-1}$ during the whole process of consolidation. Then the samples were cooled to room temperature at a rate of $10^{\circ} \mathrm{C} \mathrm{min}{ }^{-1}$. The sintered alloys are denoted as W-Y-Sc, W-Y, W-Y-La, W-Y-Ti, W-Y-Zr and $\mathrm{W}$-Y-Hf, respectively.

\section{Characterization}

The microstructure of sintered alloys was examined by scanning electron microscopy (SEM, Hitachi Model No. S 4800) and transmission electron microscopy (TEM, JEM2100) equipped with energy-dispersive $X$-ray spectroscopy (EDX) detectors, respectively. High-resolution Xray photoelectron spectroscopy (XPS) analyses were carried out using a Thermo VG Scientific ESCALAB 250XI spectrometer with an $\mathrm{Al} \mathrm{Ka}$ source. Data were acquired and analyzed using Avantage software (v5.967). All the binding energies were calibrated by setting the $\mathrm{C} 1 \mathrm{~s}$ peak to $284.8 \mathrm{eV}$ of the surface adventitious carbon. The hot compression tests of $\mathrm{La}^{3+}$-doped, $\mathrm{Hf}^{4+}$-doped and undoped $\mathrm{W}-\mathrm{Y}_{2} \mathrm{O}_{3}$ alloys were conducted on a Gleeble-3500 thermo-simulation machine. The specimens used for the hot compression tests were $6 \mathrm{~mm}$ in diameter and $8 \mathrm{~mm}$ in height, and machined from the sintered alloys. The temperature for hot compression was $700^{\circ} \mathrm{C}$ and the stain rate was $0.01 \mathrm{~s}^{-1}$, and three tests were performed on each single-component sample.

\section{RESULTS}

\section{The effect of cation doping on the microstructure,} sinterability and mechanical property of $\mathrm{W}-\mathrm{Y}_{2} \mathrm{O}_{3}$ alloy

Fig. S1 shows the X-ray diffraction (XRD) patterns of the composite powder precursors prepared by the wet chemical method. The absence of other impurity peaks in Fig. S1 indicates that these composite powders have been reduced completely. Using the Scherrer's equation, the average grain sizes of $\mathrm{W}$ are calculated to be 57.9, 61.1, 61.2, 58.3, 62.0 and $59.7 \mathrm{~nm}$ for $\mathrm{Sc}^{3+}$-doped, undoped, $\mathrm{La}^{3+}$-doped, $\mathrm{Ti}^{4+}$-doped, $\mathrm{Zr}^{4+}$-doped and $\mathrm{Hf}^{4+}$-doped $\mathrm{W}$ $\mathrm{Y}_{2} \mathrm{O}_{3}$ composite powders, respectively. Therefore, it can be found that cation doping has no significant effect on the $\mathrm{W}$ grain size of composite powder precursors, which may originate from their uniform distribution in composite powders. Fig. 1a-f present the etched surfaces of undoped $\mathrm{W}-\mathrm{Y}_{2} \mathrm{O}_{3}$ and cation-doped $\mathrm{W}-\mathrm{Y}_{2} \mathrm{O}_{3}$ alloys after sintering at $1600^{\circ} \mathrm{C}$. The average sizes of second phase particles were calculated statistically based on about 500 intergranular oxide particles, and the calculated values are summarized in Table S1. In undoped $\mathrm{W}-\mathrm{Y}_{2} \mathrm{O}_{3}$ alloy, the oxide second phase particles possess an average size of $448 \mathrm{~nm}$. After $\mathrm{Sc}^{3+}$ doping, the average size of oxide particles increases to $478 \mathrm{~nm}$, as shown in Fig. 1a. For another trivalent cation $\mathrm{La}^{3+}$, in contrast, its doping significantly suppresses the average size of oxide particles to only $96 \mathrm{~nm}$ (Fig. 1c and Table S1) under the same sintering condition. Similarly, the doping effect of tetravalent cations on the size of oxide particles also depends on the cation dopant species. The $\mathrm{Ti}^{4+}$-doped $\mathrm{W}-\mathrm{Y}_{2} \mathrm{O}_{3}$ alloy exhibits a larger size of $\mathrm{Y}_{2} \mathrm{O}_{3}$ particles $(460 \mathrm{~nm}$, Table S1) than the undoped $\mathrm{W}-\mathrm{Y}_{2} \mathrm{O}_{3}$ alloy. However, the doping with $\mathrm{Zr}^{4+}$ has a slightly inhibitory effect on the coarsening of $\mathrm{Y}_{2} \mathrm{O}_{3}$ second phase particles, and the $\mathrm{Y}_{2} \mathrm{O}_{3}$ particles in $\mathrm{Zr}^{4+}$-doped $\mathrm{W}-\mathrm{Y}_{2} \mathrm{O}_{3}$ alloy have an average size of $314 \mathrm{~nm}$. Among all the tetravalent cations employed in our work, $\mathrm{Hf}^{4+}$ is the most effective dopant to limit $\mathrm{Y}_{2} \mathrm{O}_{3}$ growth, and an average size of $123 \mathrm{~nm}$ is obtained after sintering at $1600^{\circ} \mathrm{C}$. Fig. S2 shows the distribution of oxide particle sizes in each alloy. Clearly, for the $\mathrm{Sc}^{3+}$ and $\mathrm{Ti}^{4+}$ dopants, the changes of size distributions are not obvious compared with the undoped alloy, although the oxides in corresponding cation-doped alloys are coarsened. In contrast, $\mathrm{La}^{3+}, \mathrm{Hf}^{4+}$ and $\mathrm{Zr}^{4+}$ dopants could not only significantly refine the oxide sizes but also shrink their size distributions. That is, the oxide particles in 


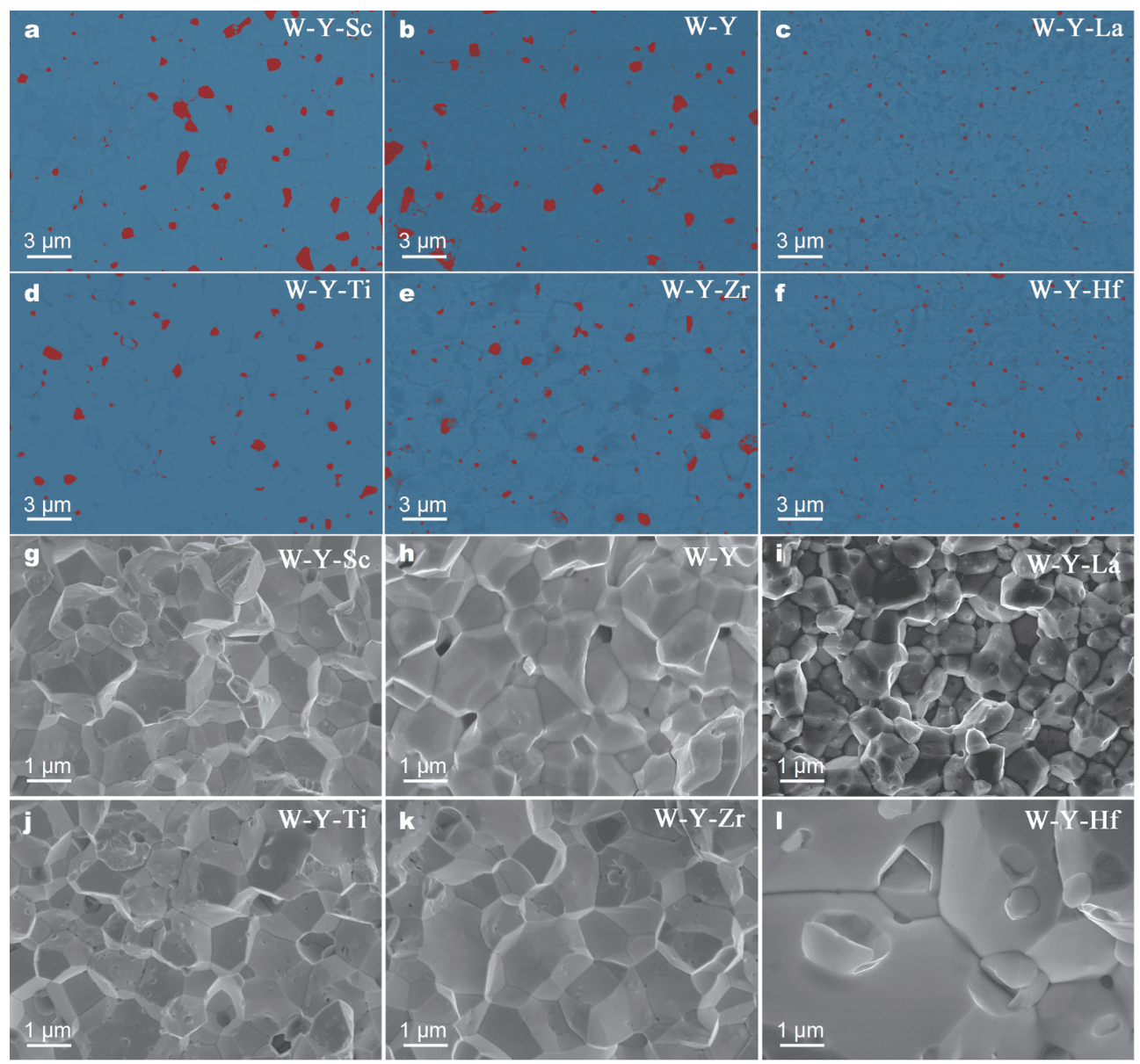

Figure 1 (a-f) Etched surfaces and (g-l) fracture surfaces of undoped $\mathrm{W}-\mathrm{Y}_{2} \mathrm{O}_{3}$ and cation-doped $\mathrm{W}-\mathrm{Y}_{2} \mathrm{O}_{3}$ alloys sintered at $1600^{\circ} \mathrm{C}$, including $(\mathrm{a}$, g) $\mathrm{Sc}^{3+}$-doped W- $\mathrm{Y}_{2} \mathrm{O}_{3}$ alloy, (b, h) undoped W- $\mathrm{Y}_{2} \mathrm{O}_{3}$ alloy, (c, i) La ${ }^{3+}$-doped $\mathrm{W}-\mathrm{Y}_{2} \mathrm{O}_{3}$ alloy, (d, j) $\mathrm{Ti}^{4+}$-doped W- $\mathrm{Y}_{2} \mathrm{O}_{3}$ alloy, (e, k) $\mathrm{Zr}^{4+}$-doped W- $\mathrm{Y}_{2} \mathrm{O}_{3}$ alloy and (f, l) $\mathrm{Hf}^{4+}$-doped $\mathrm{W}-\mathrm{Y}_{2} \mathrm{O}_{3}$ alloy. The $\mathrm{W}$ matrix in $(\mathrm{a}-\mathrm{f})$ is denoted by the blue contrast and intergranular second phase particles are denoted by the red contrast.

these cation-doped alloys have more uniform sizes. In order to exclude the influence of dopant concentration on the refinement of oxide particles, especially for the $\mathrm{Sc}^{3+}$ and $\mathrm{Ti}^{4+}$ doping, $\mathrm{Sc}^{3+}$ or $\mathrm{Ti}^{4+}$ dopants with different concentrations from 0.4 to 2 vol\% were added in the W$\mathrm{Y}_{2} \mathrm{O}_{3}$ composite nanopowder precursor, and the results are presented in Figs S3 and S4, respectively. It can be found that, whether $\mathrm{Sc}^{3+}$ doping or $\mathrm{Ti}^{4+}$ doping, the average sizes of intergranular $\mathrm{Y}_{2} \mathrm{O}_{3}$ particles all increase with the increasing cation dopant concentration. Besides, the fraction of large-sized $\mathrm{Y}_{2} \mathrm{O}_{3}$ particles also has a positive correlation with the cation dopant concentration, which indicates, different from $\mathrm{La}^{3+}, \mathrm{Zr}^{4+}$ and $\mathrm{Hf}^{4+}$ doping, $\mathrm{Sc}^{3+}$ and $\mathrm{Ti}^{4+}$ doping cannot refine the intergranular $\mathrm{Y}_{2} \mathrm{O}_{3}$ particles, independent with their dopant concentration.

Fig. 1g-l show the fracture surfaces of undoped and cation-doped $\mathrm{W}-\mathrm{Y}_{2} \mathrm{O}_{3}$ alloys. The sinterability of $\mathrm{W}$ skeleton in undoped and cation-doped $\mathrm{W}-\mathrm{Y}_{2} \mathrm{O}_{3}$ alloys can be reflected to a large extent by the average $\mathrm{W}$ grain size calculated from these micrographs (about 500 randomly selected $\mathrm{W}$ grains). Noteworthily, the trivalent cationdoped $\mathrm{W}-\mathrm{Y}_{2} \mathrm{O}_{3}$ alloys and tetravalent cation-doped $\mathrm{W}$ $\mathrm{Y}_{2} \mathrm{O}_{3}$ alloys present completely opposite grain growth trend. Typically, for the trivalent cation doping, the $\mathrm{W}$ grain growth is gradually suppressed as the oxide particles are refined from $\mathrm{Sc}^{3+}$ to $\mathrm{La}^{3+}$ doping, as summarized in Table S1. Conversely, for the tetravalent cation doping, W grain growth is promoted with the refinement of oxide particles from $\mathrm{Ti}^{4+}, \mathrm{Zr}^{4+}$ to $\mathrm{Hf}^{4+}$ doping.

Given a system containing finely dispersed oxide second phase particles, the grain microstructure state of metal matrix could be attributed to the pinning force exerted by the intergranular oxide particles. If the oxide 
particles are considered as immovable, the limiting grain size of metal matrix should be proportional to the particle radius and inversely proportional to the volume fraction of intergranular particles under a certain sintering condition according to the Zener relation [30,31]. For the same volume fraction of oxide, smaller particle size is more effective at pinning grain boundary migration [32]. Therefore, compared with undoped $\mathrm{W}-\mathrm{Y}_{2} \mathrm{O}_{3}$ alloy, it is understandable that $\mathrm{Sc}^{3+}$-doped and $\mathrm{Ti}^{4+}$-doped $\mathrm{W}-\mathrm{Y}_{2} \mathrm{O}_{3}$ alloys both have larger $\mathrm{W}$ grain sizes $(1160$ and $1200 \mathrm{~nm}$, respectively) because of the coarsening of $\mathrm{Y}_{2} \mathrm{O}_{3}$ second phase particles. And it is also reasonable that $\mathrm{La}^{3+}$-doped $\mathrm{W}-\mathrm{Y}_{2} \mathrm{O}_{3}$ alloy exhibits a smaller $\mathrm{W}$ grain size $(770 \mathrm{~nm})$ than undoped $\mathrm{W}-\mathrm{Y}_{2} \mathrm{O}_{3}$ alloy due to the refinement of $\mathrm{Y}_{2} \mathrm{O}_{3}$ particles. But it is abnormal that $\mathrm{Zr}^{4+}$ and $\mathrm{Hf}^{4+}$ doping increase the $\mathrm{W}$ grain size compared with undoped $\mathrm{W}-\mathrm{Y}_{2} \mathrm{O}_{3}$ alloy, considering that they also refine the oxide particles remarkably, as shown in Table S1. Based on previous studies, $\mathrm{W}$ grain growth and $\mathrm{W}$ matrix densification are ascribed to grain boundary diffusion or surface diffusion [33,34], and the present results indicate that cation doping probably play a key role in altering the diffusivity of $\mathrm{W}$, which exactly is the origin of this doping effect $[35,36]$. For example, the diffusivity of $\mathrm{W}$ is supposed to be accelerated by $\mathrm{Hf}^{4+}$ doping, thus improving the sinterability of $\mathrm{W}$ matrix. However, for the case of $\mathrm{La}^{3+}$ doping, the diffusivity of $\mathrm{W}$ might be suppressed, which leads to the retardation of $\mathrm{W}$ grain growth. This speculation will be discussed detailedly in the later section.

In consideration of the significant microstructural change caused by cation doping, including the size of intergranular $\mathrm{Y}_{2} \mathrm{O}_{3}$ particles and the grain size of $\mathrm{W}$ matrix, the mechanical properties of cation-doped $\mathrm{W}$ $\mathrm{Y}_{2} \mathrm{O}_{3}$ alloys should be affected dramatically. Taking $\mathrm{La}^{3+}$-doped and $\mathrm{Hf}^{4+}$-doped $\mathrm{W}-\mathrm{Y}_{2} \mathrm{O}_{3}$ alloys with the most obvious microstructural change for examples, Fig. 2 presents the true stress-strain curves of these two alloys tested at $700^{\circ} \mathrm{C}$. The curve of undoped $\mathrm{W}-\mathrm{Y}_{2} \mathrm{O}_{3}$ alloy is also provided for comparison. The compressive properties measured from Fig. 2 are summarized and listed in Table S2. It can be seen that the undoped $\mathrm{W}-\mathrm{Y}_{2} \mathrm{O}_{3}$ alloy has an ultimate strength of $744.8 \mathrm{MPa}$, together with a strain-to-failure of $30.5 \%$ and a uniform shrinkage of $17.9 \%$. After $\mathrm{La}^{3+}$ doping, the alloy exhibits both enhanced strength $(800.7 \mathrm{MPa})$ and improved ductility (37.8\%). Meanwhile, the uniform shrinkage of $\mathrm{La}^{3+}$-doped $\mathrm{W}-\mathrm{Y}_{2} \mathrm{O}_{3}$ alloy is $30.7 \%$ (increasing from $17.9 \%$ to $23.4 \%$ ) higher than the undoped $\mathrm{W}-\mathrm{Y}_{2} \mathrm{O}_{3}$ alloy. However, $\mathrm{Hf}^{4+}$-doping leads to a remarkable decrease in ultimate

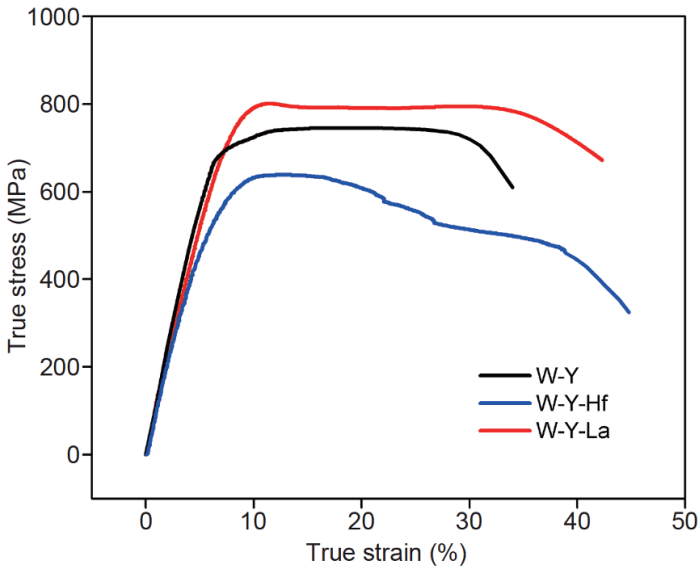

Figure 2 Compressive true stress-strain curves of undoped, $\mathrm{La}^{3+}$ - and $\mathrm{Hf}^{4+}$-doped $\mathrm{W}-\mathrm{Y}_{2} \mathrm{O}_{3}$ alloys at $700^{\circ} \mathrm{C}$.

strength (638.2 MPa), although its strain-to-failure increases evidently to $38.9 \%$. These results explicitly confirm that the mechanical properties of $\mathrm{W}-\mathrm{Y}_{2} \mathrm{O}_{3}$ alloys can be effectively improved by proper cation doping via tailoring their microstructures. To the best of our knowledge, cation doping, especially $\mathrm{La}^{3+}$ doping, is firstly reported to be capable of simultaneously enhancing the strength and ductility of $\mathrm{W}-\mathrm{Y}_{2} \mathrm{O}_{3}$ alloy.

\section{The characterization of cation dopant segregation}

In order to explore the role of dopant cations, the distribution of different cation dopants in corresponding alloys should be investigated firstly. Fig. 3a, c show the high angle annular dark-field-scanning TEM (HAADFSTEM) images from TEM of an intergranular oxide particle in $\mathrm{La}^{3+}$-doped and $\mathrm{Hf}^{4+}$-doped $\mathrm{W}-\mathrm{Y}_{2} \mathrm{O}_{3}$ alloys, respectively. Interestingly, it can be observed that some areas with brighter contrast than the matrix of $\mathrm{Y}_{2} \mathrm{O}_{3}$ particles appear at the $\mathrm{W} / \mathrm{Y}_{2} \mathrm{O}_{3}$ interface in both alloys. The brighter contrast is due to the higher atomic number or $\mathrm{Z}$ contrast of element, which preliminarily indicates some components in cation-doped alloys tend to segregate in the vicinity of $\mathrm{W} / \mathrm{Y}_{2} \mathrm{O}_{3}$ interface. The orange lines in these images are the routes of EDX line scan for analyzing the elemental distribution and the corresponding results are present in Fig. 3b, d, respectively. The La-M and $\mathrm{Hf}-\mathrm{M}$ signals demonstrate that $\mathrm{La}^{3+}$ and $\mathrm{Hf}^{4+}$ dopants could segregate from $\mathrm{Y}_{2} \mathrm{O}_{3}$ matrix to $\mathrm{W} / \mathrm{Y}_{2} \mathrm{O}_{3}$ interface during the process of sintering. EDX line scan of the $\mathrm{Y}_{2} \mathrm{O}_{3}$ particle in the $\mathrm{Zr}^{4+}$-doped $\mathrm{W}-\mathrm{Y}_{2} \mathrm{O}_{3}$ alloy (Fig. S5) also reveals the segregation of $\mathrm{Zr}^{4+}$ dopant at the $\mathrm{W} / \mathrm{Y}_{2} \mathrm{O}_{3}$ interface, as observed for $\mathrm{La}^{3+}$ and $\mathrm{Hf}^{4+}$ dopants. However, what calls for special attention is that the segregation 

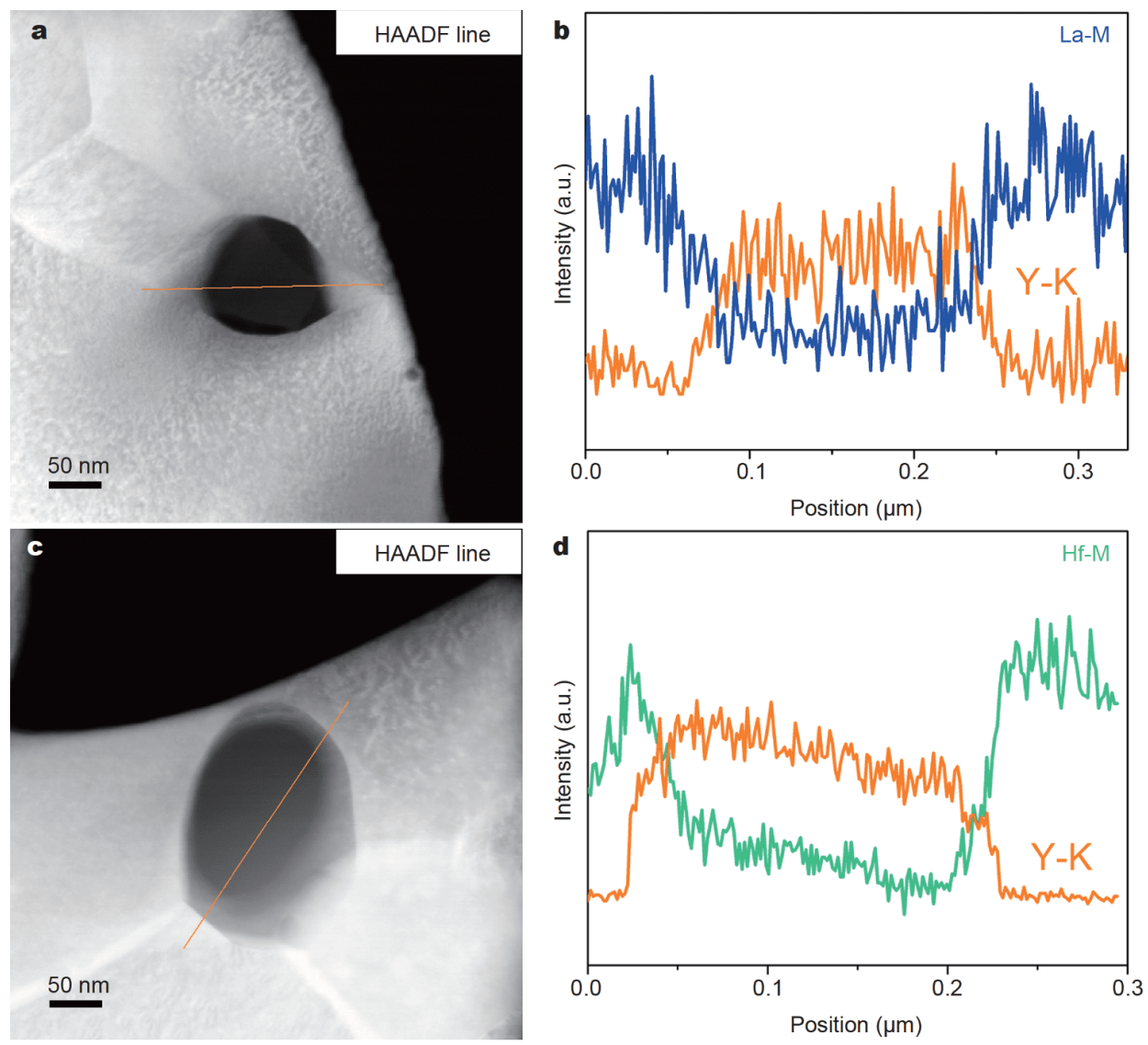

Figure 3 HAADF images from TEM of an oxide particle at W grain boundary in (a) $\mathrm{La}^{3+}$ - and (c) $\mathrm{Hf}^{4+}$-doped W- $\mathrm{Y}_{2} \mathrm{O}_{3}$ alloys, where the orange lines are the routes of EDX line scan, and the results are presented in $(b, d)$, respectively.

region in $\mathrm{Zr}^{4+}$-doped $\mathrm{W}-\mathrm{Y}_{2} \mathrm{O}_{3}$ alloy is recognized easily only in the nanosized $\mathrm{Y}_{2} \mathrm{O}_{3}$ particles. For most oxide particles with submicron size in spite of finer than that in undoped $\mathrm{W}-\mathrm{Y}_{2} \mathrm{O}_{3}$ alloy, the $\mathrm{Zr}^{4+}$ dopant is detected homogenously in the $\mathrm{Y}_{2} \mathrm{O}_{3}$ matrix, which suggests the segregation of $\mathrm{Zr}^{4+}$ dopant in the $\mathrm{W}-\mathrm{Y}_{2} \mathrm{O}_{3}$ system is less compared with $\mathrm{La}^{3+}$ and $\mathrm{Hf}^{4+}$ dopants. Accordingly, it can be found that the refinement of oxide particles is closely associated with the segregation tendency of cation dopants (Table S1). This conclusion is also supported by the elemental mapping for the $\mathrm{Y}_{2} \mathrm{O}_{3}$ particles in $\mathrm{Sc}^{3+}$ - and $\mathrm{Ti}^{4+}$-doped $\mathrm{W}-\mathrm{Y}_{2} \mathrm{O}_{3}$ alloys, as shown in Figs $\mathrm{S} 6$ and $\mathrm{S} 7$, respectively. The average sizes of oxide particles in these alloys are all larger than that in the undoped $\mathrm{W}-\mathrm{Y}_{2} \mathrm{O}_{3}$ alloy. From the EDS maps for special elements, it can be found that $\mathrm{Sc}^{3+}$ and $\mathrm{Ti}^{4+}$ dopants distribute homogeneously within the $\mathrm{Y}_{2} \mathrm{O}_{3}$ matrix without any evidence of segregation (Figs S6 and S7). This result suggests that $\mathrm{Sc}^{3+}$ and $\mathrm{Ti}^{4+}$ dopants seem to react with $\mathrm{Y}_{2} \mathrm{O}_{3}$ and form thermodynamically stable ternary oxides such as $\mathrm{Sc}-\mathrm{Y}-\mathrm{O}$ and Ti-Y-O, losing their ability to refine $\mathrm{Y}_{2} \mathrm{O}_{3}$ particles.

Fig. 4a shows a TEM image of an oxide particle in $\mathrm{La}^{3+}$ doped $\mathrm{W}-\mathrm{Y}_{2} \mathrm{O}_{3}$ alloy. It can be clearly seen that segregated areas with gray contrast appear at the $\mathrm{W} / \mathrm{Y}_{2} \mathrm{O}_{3}$ interface and their corresponding high-resolution TEM (HRTEM) images are exhibited in Fig. 4 b, c. Lattice fringes for three areas including $\mathrm{W}$ matrix, segregated area and $\mathrm{Y}_{2} \mathrm{O}_{3}$ particle can be observed clearly in these HRTEM images. Therefore, the segregation area of $\mathrm{La}^{3+}$ dopant exists in the form of crystal. Fig. $4 \mathrm{~d}-\mathrm{f}$ present the fast Fourier transform (FFT) of these three areas (denoted as 1, 2, 3, respectively) in Fig. 4c. The identical diffraction spots in Fig. 4d, e indicate the crystallographic orientation of $\mathrm{Y}_{2} \mathrm{O}_{3}$ is not altered by the segregation of $\mathrm{La}^{3+}$ dopant, suggesting the fully coherent interface relationship between the segregation area and $\mathrm{Y}_{2} \mathrm{O}_{3}$ matrix. In this regard, it is suggested that the segregation of dopant cation is a process of replacing the site of host cation Y. Therefore, the interface relationship of tungsten and segregation area still retains the initial interface relationship of tungsten 


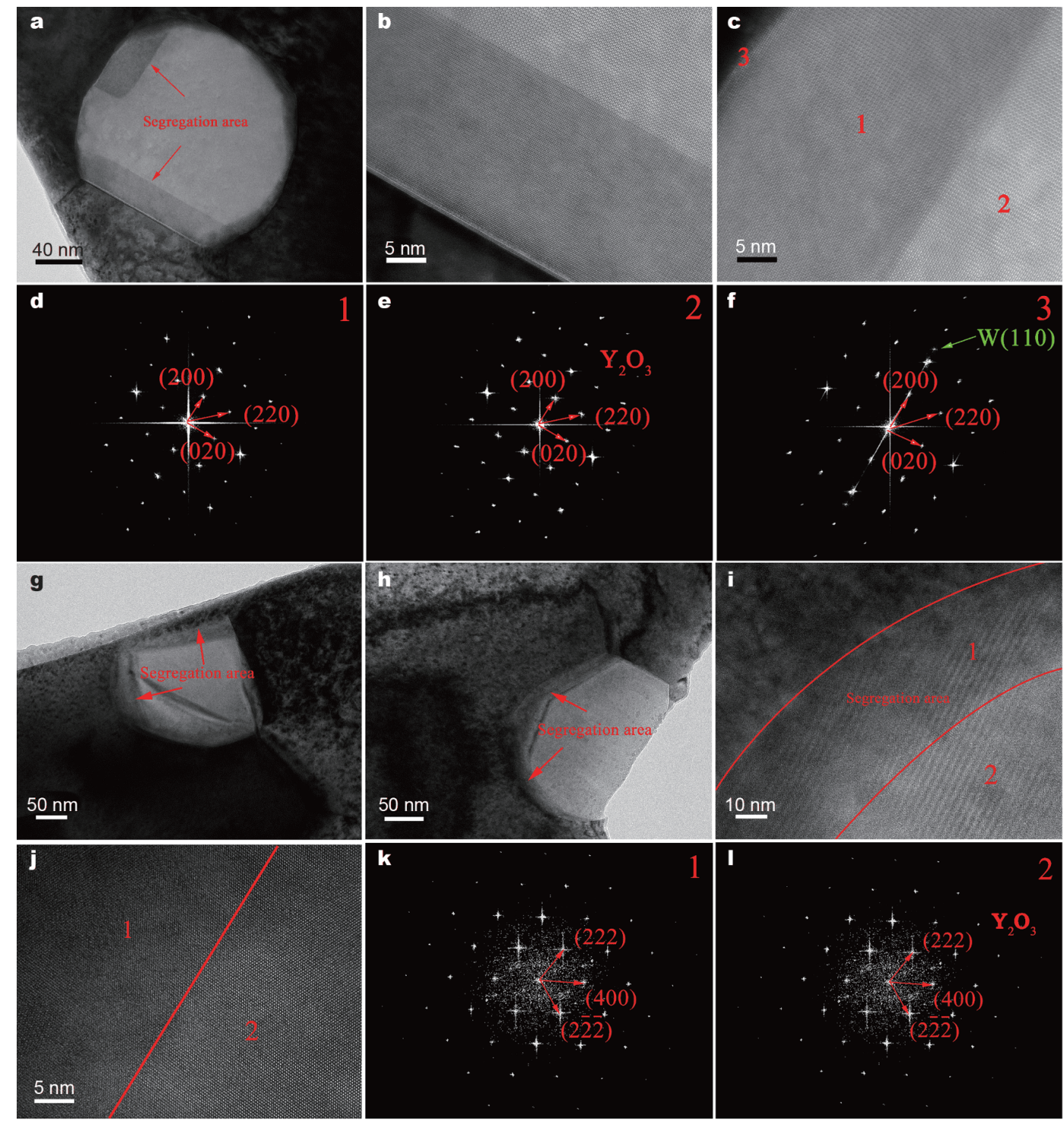

Figure 4 (a) Low-magnification TEM image of an oxide particle in $\mathrm{La}^{3+}$-doped $\mathrm{W}-\mathrm{Y}_{2} \mathrm{O}_{3}$ alloy. (b, c) HRTEM images of W/ $\mathrm{Y}_{2} \mathrm{O}_{3}$ interface in (a). $(\mathrm{d}-\mathrm{f}) \mathrm{FFT}$ of three areas (denoted as 1, 2, 3, respectively) in (c). ( $\mathrm{g}, \mathrm{h})$ Low-magnification TEM images of oxide particles in $\mathrm{Hf}^{4+}$-doped W- $\mathrm{Y}_{2} \mathrm{O}_{3}$ alloy. $(i, j)$ HRTEM images of $\mathrm{W} / \mathrm{Y}_{2} \mathrm{O}_{3}$ interface in (h). (k, l) FFT of these two areas (denoted as 1,2 , respectively) in (j).

and $\mathrm{Y}_{2} \mathrm{O}_{3}$ before segregation. Furthermore, Fig. $4 \mathrm{f}$ shows that there is a defined orientational relationship between the $\mathrm{Y}_{2} \mathrm{O}_{3}$ particles and $\mathrm{W}$ matrix, i.e., $\mathrm{W}(110) / / \mathrm{Y}_{2} \mathrm{O}_{3}(200)$. Fig. $4 \mathrm{~g}$, h show the TEM images of oxide particles in the $\mathrm{Hf}^{4+}$-doped $\mathrm{W}-\mathrm{Y}_{2} \mathrm{O}_{3}$ alloy. As observed in Fig. 4g, segregation areas with gray contrast also appear at the $\mathrm{W} / \mathrm{Y}_{2} \mathrm{O}_{3}$ interfaces. Distinct lattice fringes can also be found in the HRTEM image of segregated areas (Fig. 4i, j), indicating the segregation of $\mathrm{Hf}^{4+}$ dopant also exists in the form of crystal. Fig. $4 \mathrm{k}, \mathrm{l}$ are the FFT of the $\mathrm{Hf}^{4+}$ segregation area at the $\mathrm{W} / \mathrm{Y}_{2} \mathrm{O}_{3}$ interface and inner $\mathrm{Y}_{2} \mathrm{O}_{3}$ matrix, respectively, and verify again the fully coherent interface be- tween them. These observations directly reveal the segregation of $\mathrm{La}^{3+}$ and $\mathrm{Hf}^{4+}$ dopants at the $\mathrm{W} / \mathrm{Y}_{2} \mathrm{O}_{3}$ interfaces, which is fully consistent with the EDX line scan (Fig. 3).

\section{DISCUSSION}

The effect mechanism of cation dopant segregation on the sinterability of $\mathrm{W}$ matrix and the refinement of intergranular $\mathrm{Y}_{2} \mathrm{O}_{3}$ particles

As mentioned above, for the isovalent dopant cations such as $\mathrm{Sc}^{3+}$ and $\mathrm{La}^{3+}$, the sinterability of $\mathrm{W}$ matrix in 
cation-doped $\mathrm{W}-\mathrm{Y}_{2} \mathrm{O}_{3}$ alloys is suppressed with the increase of segregation degree (i.e., the segregation tendency of cation dopants), while for the aliovalent dopant cations such as $\mathrm{Ti}^{4+}, \mathrm{Zr}^{4+}$ and $\mathrm{Hf}^{4+}$, the segregation of cation dopants promote the sinterability of $\mathrm{W}$ matrix. According to previous study, the change of sinterability of $\mathrm{W}$ matrix is closely associated with the alteration in diffusivity of $\mathrm{W}$ owing to the cation doping [33]. In order to discover the reason behind this phenomenon, the mass transport mechanism of $\mathrm{W}$ matrix in $\mathrm{W}-\mathrm{Y}_{2} \mathrm{O}_{3}$ composite powder prepared by the wet chemical method during the low-temperature sintering process should be investigated firstly. The detailed research on this topic has been reported in our previous work [37]. Briefly, the integral and differential methods deduced from the well-known grain growth power law were used to analyze the nonisothermal sintering data $[34,38,39]$. Consequently, it was found that, for the $\mathrm{W}-\mathrm{Y}_{2} \mathrm{O}_{3}$ system, grain boundary diffusion is responsible for the mass transport mechanism during the low-temperature sintering process. Thus, according to the classical grain growth model [40], the ratelimiting mechanism for $\mathrm{W}$ grain growth in the $\mathrm{W}-\mathrm{Y}_{2} \mathrm{O}_{3}$ system will be significantly affected by the diffusion along the $\mathrm{W} / \mathrm{Y}_{2} \mathrm{O}_{3}$ interface. Due to the chemical bonding between $\mathrm{W}$ and $\mathrm{O}$ along the $\mathrm{W} / \mathrm{Y}_{2} \mathrm{O}_{3}$ interface, the diffu- sivity of $\mathrm{W}$ in the $\mathrm{W}-\mathrm{Y}_{2} \mathrm{O}_{3}$ system decreases remarkably, thus suppressing the sinterability of $\mathrm{W}$ matrix $[37,41]$.

Once cation dopants segregate to the $\mathrm{W} / \mathrm{Y}_{2} \mathrm{O}_{3}$ interface, the chemical bonding along this interface might be affected prominently, influencing the sinterability of $\mathrm{W}$ matrix. To verify this speculation, narrow-scan XPS spectra of W $4 \mathrm{f}$ core level for undoped and cation-doped $\mathrm{W}-\mathrm{Y}_{2} \mathrm{O}_{3}$ alloys were tested and the results are presented in Fig. 5. Interestingly, it is found that the fitted peak area assigned to $\mathrm{W}^{6+}$ state is gradually increased with the increase of segregation degree for the trivalent cation-doped $\mathrm{W}-\mathrm{Y}_{2} \mathrm{O}_{3}$ alloys. However, for the tetravalent cation-doped $\mathrm{W}-\mathrm{Y}_{2} \mathrm{O}_{3}$ alloys, the fitted peak area attributed to $\mathrm{W}^{6+}$ state decreases with the increase of segregation degree and reaches the minimum for the $\mathrm{Hf}^{4+}$-doped alloy. The oxidized $\mathrm{W}$ observed from XPS data can be mainly attributed to the $\mathrm{W}-\mathrm{O}$ bond formed along the $\mathrm{W} / \mathrm{Y}_{2} \mathrm{O}_{3}$ interface. For comparison, the XPS results of reduced powders are also provided, as shown in Fig. S8. It can be found that the fitted peak assigned to $\mathrm{W}^{6+}$ state appear in all the reduced powders. The oxidized $\mathrm{W}$ in reduced powders mainly results from the oxidation film formed on $\mathrm{W}$ particle surfaces due to their high surface activity, thus the oxidation film is difficult to be reduced completely. Besides, we also find that there is no significant
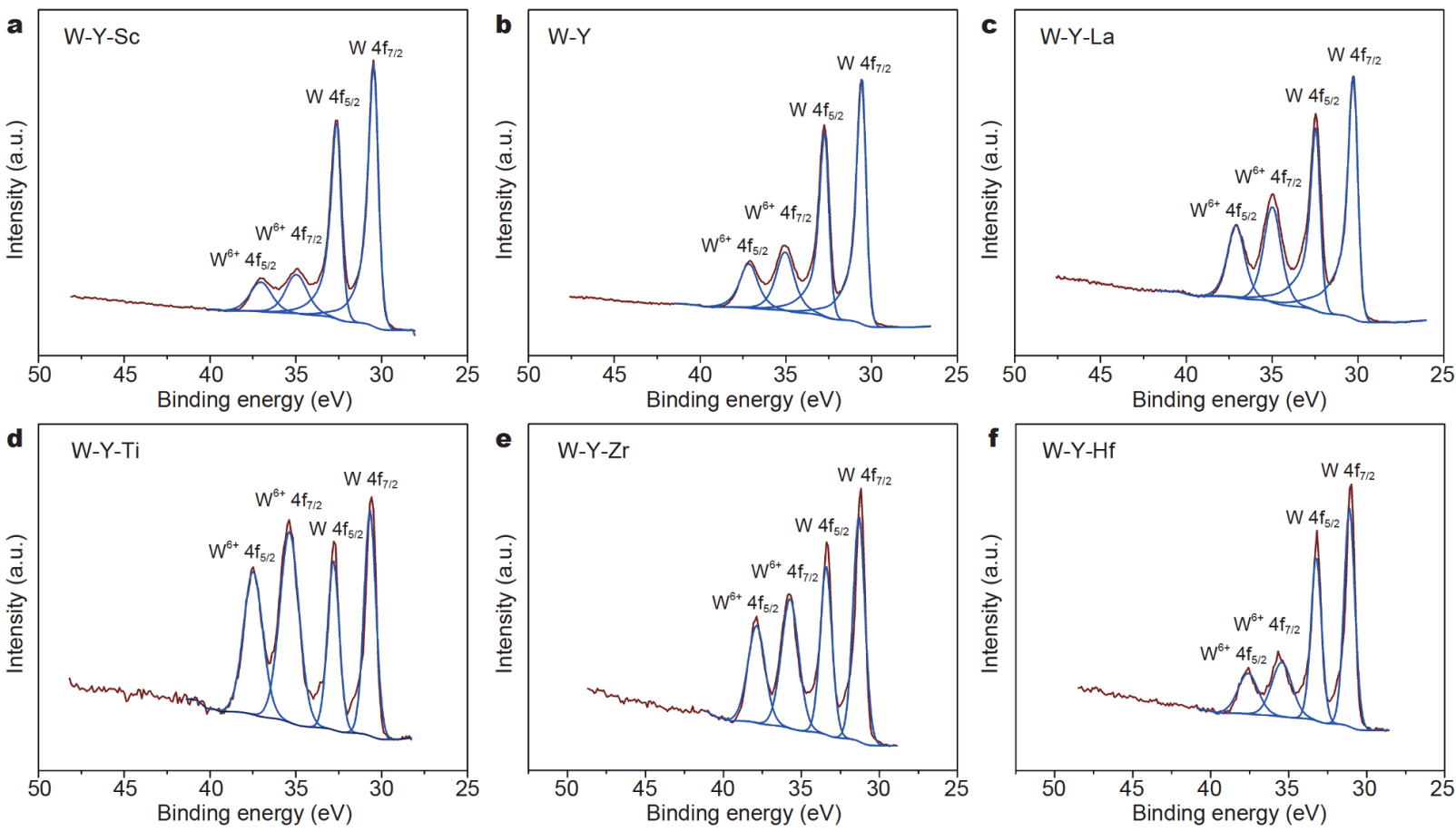

Figure 5 Narrow-scan XPS spectra of W $4 \mathrm{f}$ core level for undoped and cation-doped $\mathrm{W}-\mathrm{Y}_{2} \mathrm{O}_{3}$ alloys, including (a) $\mathrm{Sc}^{3+}$-doped $\mathrm{W}-\mathrm{Y}_{2} \mathrm{O}_{3}$ alloy, (b) undoped W- $\mathrm{Y}_{2} \mathrm{O}_{3}$ alloy, (c) $\mathrm{La}^{3+}$-doped W- $\mathrm{Y}_{2} \mathrm{O}_{3}$ alloy, (d) $\mathrm{Ti}^{4+}$-doped W- $\mathrm{Y}_{2} \mathrm{O}_{3}$ alloy, (e) $\mathrm{Zr}^{4+}$-doped $\mathrm{W}-\mathrm{Y}_{2} \mathrm{O}_{3}$ alloy and (f) $\mathrm{Hf}{ }^{4+}$-doped W- $\mathrm{Y}_{2} \mathrm{O}_{3}$ alloy. 
difference in the corresponding fitted peak area among these reduced powders, which might be attributed to the homogeneous distribution of dopant cations in reduced powders rather than the segregation state after subsequent sintering. Thus, it can be concluded that the amount of $\mathrm{W}-\mathrm{O}$ bonds is increased by $\mathrm{La}^{3+}$ dopant segregation, while it is reduced by $\mathrm{Hf}^{4+}$ dopant segregation. This result can be further supported by the density functional theory (DFT)-calculated average magnetization of $\mathrm{W}$ atoms. Specially, the average magnetizations of $\mathrm{W}$ atoms with and without $\mathrm{La}^{3+}$ dopant segregating to interface are very close (1.9 and $2.0 \mu_{\mathrm{B}}$, respectively), which results from their almost identical chemical states. Nevertheless, with $\mathrm{Hf}^{4+}$ dopant segregating to $\mathrm{W} / \mathrm{Y}_{2} \mathrm{O}_{3}$ interface, the average magnetization of $\mathrm{W}$ atoms drops to $1.3 \mu_{\mathrm{b}}$, suggesting the oxidized $\mathrm{W}$, i.e., $\mathrm{W}-\mathrm{O}$ bond decreases significantly. The reason behind might be associated with the oxygen affinity of different cations. For example, the oxygen affinity of $\mathrm{Hf}^{4+}\left(-808.4 \mathrm{~kJ} \mathrm{~mol}^{-1}\right.$, corresponding oxide formation energy, per mol cation) is much higher than that of $\mathrm{Y}^{3+}\left(-681.3 \mathrm{~kJ} \mathrm{~mol}^{-1}\right)$, resulting in partially oxidized $\mathrm{W}$ along the $\mathrm{W} / \mathrm{Y}_{2} \mathrm{O}_{3}$ interface being reduced by the segregated $\mathrm{Hf}^{4+}$ dopant. As a consequence, the activation energy for the $\mathrm{W}$ diffusion along the $\mathrm{W} /$ $\mathrm{Y}_{2} \mathrm{O}_{3}$ interface declines greatly by the unleashed $\mathrm{W}$ atoms due to the cleavage of $\mathrm{W}-\mathrm{O}$ bonds, which promotes the sinterability of $\mathrm{W}$ matrix. Thus, the resulting grain microstructure in the $\mathrm{Hf}^{4+}$-doped alloy is coarsened, as observed in Fig. 11. For the $\mathrm{La}^{3+}$ cation-doped $\mathrm{W}-\mathrm{Y}_{2} \mathrm{O}_{3}$ alloy, however, the oxygen affinity of $\mathrm{La}^{3+}\left(-626.7 \mathrm{~kJ} \mathrm{~mol}^{-1}\right)$ is lower than that of $\mathrm{Y}^{3+}$, which is beneficial to the oxidation of $\mathrm{W}$ atoms along the interface after segregation. Coupled with the increased W/oxide interface area caused by the refined oxide particles, the dramatically increased $\mathrm{W}-\mathrm{O}$ bonds will constrain the diffusion of $\mathrm{W}$ atoms along the $\mathrm{W} / \mathrm{Y}_{2} \mathrm{O}_{3}$ interface, suppressing the sinterability of $\mathrm{W}$ matrix. As a result, the grain size of $\mathrm{W}$ in the $\mathrm{La}^{3+}$-doped $\mathrm{W}-\mathrm{Y}_{2} \mathrm{O}_{3}$ alloy is refined (Fig. 1i).

Next, the effect mechanism of cation dopant segregation on the refinement of intergranular $\mathrm{Y}_{2} \mathrm{O}_{3}$ particles is studied. According to our previous study, from the view of thermodynamics, coarsening of the intergranular $\mathrm{Y}_{2} \mathrm{O}_{3}$ second phase particle is driven by the reduction in $\mathrm{W} /$ $\mathrm{Y}_{2} \mathrm{O}_{3}$ interfacial energy [37]. From the view of kinetics, Ostwald ripening is the mechanism acting to determine the diffusion path of $\mathrm{Y}_{2} \mathrm{O}_{3}$ [42]. Specially, in order to drive a $\mathrm{W} / \mathrm{Y}_{2} \mathrm{O}_{3}$ interface to move (i.e., coarsening of $\mathrm{Y}_{2} \mathrm{O}_{3}$ particle), the atoms in a $\mathrm{Y}_{2} \mathrm{O}_{3}$ particle have to diffuse through the $\mathrm{W} / \mathrm{W}$ grain boundary and then reprecipitate into another larger $\mathrm{Y}_{2} \mathrm{O}_{3}$ particle [37].
In order to explain the refinement of $\mathrm{Y}_{2} \mathrm{O}_{3}$ particle in the cation-doped $\mathrm{W}-\mathrm{Y}_{2} \mathrm{O}_{3}$ alloy, the dual effect of cation dopant segregation on the $\mathrm{W} / \mathrm{Y}_{2} \mathrm{O}_{3}$ interfacial energy and $\mathrm{Y}_{2} \mathrm{O}_{3}$ diffusion should be considered. Here, DFT calculation was performed for atomic configuration optimization and interfacial energy calculations (see Fig. S9). The detailed calculation process is described in Supplementary information, and the corresponding interface formation energy results with and without cation doping are demonstrated in Fig. 6. It can be found that with $\mathrm{La}^{3+}$ or $\mathrm{Hf}^{4+}$ doping, the interface formation energy is lower than the undoped case. To be more specific, at $1600^{\circ} \mathrm{C}$, the $\mathrm{W} / \mathrm{Y}_{2} \mathrm{O}_{3}$ interfacial energy is calculated as $0.59 \mathrm{~J} \mathrm{~m}^{-2}$ for the undoped case, and 0.15 and $0.35 \mathrm{~J} \mathrm{~m}^{-2}$ for the $\mathrm{La}^{3+}$ - and $\mathrm{Hf}^{4+}$-doped cases, respectively. Therefore, thermodynamically, the driving force for $\mathrm{Y}_{2} \mathrm{O}_{3}$ grain growth declines. Kinetically, the cation dopant segregating to $\mathrm{W} / \mathrm{Y}_{2} \mathrm{O}_{3}$ interface is expected to block the diffusion of $\mathrm{Y}_{2} \mathrm{O}_{3}$ from the $\mathrm{Y}_{2} \mathrm{O}_{3}$ matrix to the $\mathrm{W}$ grain boundary (i.e., the coarsening of $\mathrm{Y}_{2} \mathrm{O}_{3}$ ), slowing or inhibiting the growth of $\mathrm{Y}_{2} \mathrm{O}_{3}$.

\section{The origin of enhanced mechanical properties in cation- doped $\mathrm{W}-\mathrm{Y}_{2} \mathrm{O}_{3}$ alloy}

Next, the origin of enhanced strength and ductility of cation-doped $\mathrm{W}-\mathrm{Y}_{2} \mathrm{O}_{3}$ alloys was analyzed. As mentioned above, these improved properties affirmatively benefit from the microstructure actually formed through cation doping. In terms of $\mathrm{La}^{3+}$-doped $\mathrm{W}-\mathrm{Y}_{2} \mathrm{O}_{3}$ alloy, the intergranular oxide particles have an average size of only $96 \mathrm{~nm}$, which could produce a more frequent interaction between the $\mathrm{W}$ grain boundary and oxide particles than undoped $\mathrm{W}-\mathrm{Y}_{2} \mathrm{O}_{3}$ alloy, leading to the ultrafine $\mathrm{W}$ grain

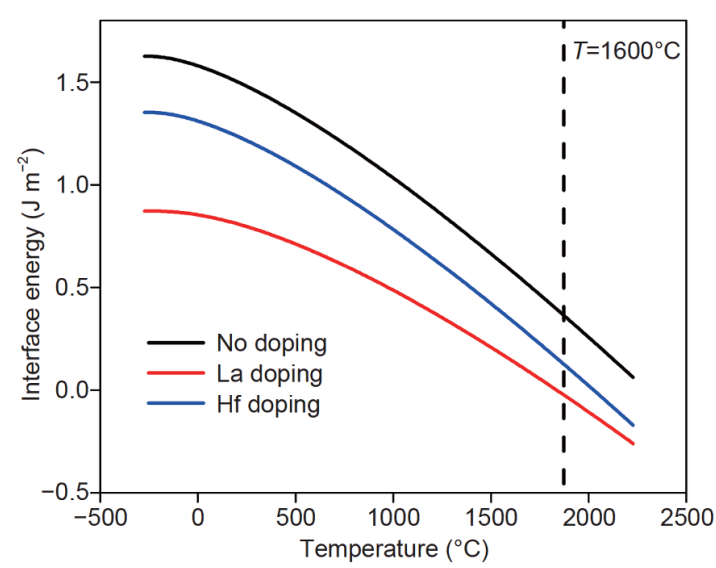

Figure 6 Interface formation energy as a function of temperature for undoped $\mathrm{W}(110) / \mathrm{Y}_{2} \mathrm{O}_{3}(200)$ interface, $\mathrm{La}^{3+}$ - and $\mathrm{Hf}^{4+}$-doped interface. 
$(770 \mathrm{~nm})$ and ensuing high strength. The corresponding strengthening mechanism can be understood via the Hall-Petch equation where the strength of materials is inversely proportional to their grain size. Therefore, the high strength of $\mathrm{La}^{3+}$-doped alloy mainly originates from its refined $\mathrm{W}$ grains. In contrary, the coarsening of $\mathrm{W}$ matrix grain is induced by $\mathrm{Hf}^{4+}$ doping. Thus, it follows that the strength of $\mathrm{Hf}^{4+}$-doped $\mathrm{W}-\mathrm{Y}_{2} \mathrm{O}_{3}$ alloy decreases dramatically [43]. On the other hand, the refined oxide particles in both $\mathrm{La}^{3+}$ - and $\mathrm{Hf}^{4+}$-doped $\mathrm{W}-\mathrm{Y}_{2} \mathrm{O}_{3}$ alloys are conductive to the improvement of their ductility. Generally speaking, due to deformation incompatibility, large strain concentration can be easily introduced at oxide particles, which will give rise to the decohesion along the matrix/oxide interface and the fracture of oxide particle during load. Therefore, the intergranular oxide particles are preferential sites for crack initiation, especially for the larger (submicron or even micron) particles with lower fracture strength, deteriorating the ductility of W-based alloy [9]. Fortunately, the intergranular oxide particles in $\mathrm{La}^{3+}$-doped and $\mathrm{Hf}^{4+}$-doped $\mathrm{W}-\mathrm{Y}_{2} \mathrm{O}_{3}$ alloys are all refined conspicuously, which alleviates the tendency for fracture and decohesion at these particles and then enhances the total strain before failure. Adopting the model that relates the macroscopic elongation to intergranular particles, the strain-to-failure of different cation-doped ODS-W alloys can be understood well $[44,45]$. From this model, it can be obviously found that given a certain amount of intergranular particles, the smaller the intergranular particle size is, the higher the ductility of $\mathrm{W}$ material is. Therefore, reducing the intergranular particle size is an effective method to enhance the ductility of ODS-W alloy. But, noteworthily, the total elongation of $\mathrm{La}^{3+}$-doped $\mathrm{W}-\mathrm{Y}_{2} \mathrm{O}_{3}$ alloy is slightly smaller than that of $\mathrm{Hf}^{4+}$-doped $\mathrm{W}-\mathrm{Y}_{2} \mathrm{O}_{3}$ alloy. This phenomenon might arise from the inverse strength-ductility relationship $[46,47]$.

\section{CONCLUSION}

All long, large-sized intergranular oxide second phase particle in ODS alloys is always a bottleneck limiting their widespread applications. In this work, taking $\mathrm{Y}_{2} \mathrm{O}_{3}$ dispersion-strengthened $\mathrm{W}$ alloy for example, various cation-doped $\mathrm{W}-\mathrm{Y}_{2} \mathrm{O}_{3}$ alloys have been developed successfully via a wet chemical method and subsequent low-temperature sintering. It was found that proper cation doping, especially $\mathrm{La}^{3+}$ and $\mathrm{Hf}^{4+}$ doping, could not only significantly refine and disperse intergranular $\mathrm{Y}_{2} \mathrm{O}_{3}$ particles, but also improve the sinterability of $\mathrm{W}$ matrix. As a result, the strength and ductility of $\mathrm{W}-\mathrm{Y}_{2} \mathrm{O}_{3}$ alloy are enhanced simultaneously. After careful characterizations, it was confirmed that cation dopant segregation at the W/ $\mathrm{Y}_{2} \mathrm{O}_{3}$ interface is the origin of these doping effects. The chemical bonding along the $\mathrm{W} / \mathrm{Y}_{2} \mathrm{O}_{3}$ interface can be changed by dopant segregation, influencing the ratelimiting mechanism for $\mathrm{W}$ grain growth, which explains well the difference of $\mathrm{W}$ grain size in cation-doped $\mathrm{W}$ $\mathrm{Y}_{2} \mathrm{O}_{3}$ alloys. For the refinement of intergranular $\mathrm{Y}_{2} \mathrm{O}_{3}$ particles, it can be understood well from both thermodynamic and kinetic views. For the former, it is the reduction in $\mathrm{W} / \mathrm{Y}_{2} \mathrm{O}_{3}$ interfacial energy induced by cation dopant segregation that weakens the thermodynamic driving force for $\mathrm{Y}_{2} \mathrm{O}_{3}$ coarsening. For the latter, the diffusion path for $\mathrm{Y}_{2} \mathrm{O}_{3}$ coarsening is blocked by the segregation area at the $\mathrm{W} / \mathrm{Y}_{2} \mathrm{O}_{3}$ interface.

Based on the results in our work, we believe that the cation doping introduced by the wet chemical method and subsequent low-temperature sintering is an extremely promising way to fabricate high-performance ODS alloys with enhanced strength and ductility. More importantly, this approach can also be employed to improve the hightemperature stability of oxide second phase particles under extreme working environment.

Received 20 June 2020; accepted 7 August 2020;

published online 11 November 2020

1 Park LJ, Ryu HJ, Hong SH, et al. Microstructure and mechanical behavior of mechanically alloyed ODS Ni-base superalloy for aerospace gas turbine application. Adv Perform Mater, 1998, 5: 279-290

2 Voevodin A, Zabinski J. Nanocomposite and nanostructured tribological materials for space applications. Compos Sci Tech, 2005, 65: 741-748

3 Ukai S, Harada M, Okada H, et al. Alloying design of oxide dispersion strengthened ferritic steel for long life FBRs core materials. J Nucl Mater, 1993, 204: 65-73

4 Zheng X, Bai R, Wang DH, et al. Research development of refractory metal materials used in the field of aerospace. Rare Metal Mat Eng, 2011, 40: 1871-1875

5 Luo LM, Tan XY, Chen HY, et al. Preparation and characteristics of $\mathrm{W}-1 w \mathrm{wt} \%$ TiC alloy via a novel chemical method and spark plasma sintering. Powder Tech, 2015, 273: 8-12

6 Tan $\mathrm{X}$, Luo L, Chen $\mathrm{H}$, et al. Mechanical properties and microstructural change of $\mathrm{W}-\mathrm{Y}_{2} \mathrm{O}_{3}$ alloy under helium irradiation. Sci Rep, 2015, 5: 12755

7 Vieider G, Merola M, Bonal JP, et al. European development of the ITER divertor target. Fusion Eng Des, 1999, 46: 221-228

8 Cockeram BV. The fracture toughness and toughening mechanism of commercially available unalloyed molybdenum and oxide dispersion strengthened molybdenum with an equiaxed, large grain structure. Metall Mat Trans A, 2009, 40: 2843-2860

9 Liu G, Zhang GJ, Jiang F, et al. Nanostructured high-strength molybdenum alloys with unprecedented tensile ductility. Nat Mater, 2013, 12: 344-350

10 Huang L, Jiang L, Topping TD, et al. In situ oxide dispersion 
strengthened tungsten alloys with high compressive strength and high strain-to-failure. Acta Mater, 2017, 122: 19-31

11 Li X, Liu W, Xu Y, et al. Radiation resistance of nano-crystalline iron: Coupling of the fundamental segregation process and the annihilation of interstitials and vacancies near the grain boundaries. Acta Mater, 2016, 109: 115-127

12 Ueda Y, Schmid K, Balden M, et al. Baseline high heat flux and plasma facing materials for fusion. Nucl Fusion, 2017, 57: 092006

13 El-Genk MS, Tournier JM. A review of refractory metal alloys and mechanically alloyed-oxide dispersion strengthened steels for space nuclear power systems. J Nucl Mater, 2005, 340: 93-112

14 Raman L, Gothandapani K, Murty BS. Austenitic oxide dispersion strengthened steels: A review. Def Sc Jl, 2016, 66: 316

$15 \mathrm{Hu} \mathrm{W}, \mathrm{Yu} \mathrm{L}, \mathrm{Ma} \mathrm{Z}$, et al. W- $\mathrm{Y}_{2} \mathrm{O}_{3}$ composite nanopowders prepared by freeze-drying method and its sintering characteristics. J Alloys Compd, 2019, 806: 127-135

$16 \mathrm{Hu} \mathrm{W}$, Dong Z, Yu L, et al. Synthesis of $\mathrm{W}-\mathrm{Y}_{2} \mathrm{O}_{3}$ alloys by freezedrying and subsequent low temperature sintering: Microstructure refinement and second phase particles regulation. J Mater Sci Tech, 2020, 36: 84-90

17 Wahlberg S, Yar MA, Abuelnaga MO, et al. Fabrication of nanostructured $\mathrm{W}-\mathrm{Y}_{2} \mathrm{O}_{3}$ materials by chemical methods. J Mater Chem, 2012, 22: 12622

$18 \mathrm{Ma} \mathrm{Q}$, Lan F, Li X, et al. The effect of S doping on the superconductivity and nematicity transition of FeSe. Scripta Mater, 2020, 176: 88-93

19 Miller MK, Russell KF, Hoelzer DT. Characterization of precipitates in MA/ODS ferritic alloys. J Nucl Mater, 2006, 351: 261268

20 de Castro V, Marquis EA, Lozano-Perez S, et al. Stability of nanoscale secondary phases in an oxide dispersion strengthened Fe-12Cr alloy. Acta Mater, 2011, 59: 3927-3936

21 Xie ZM, Liu R, Zhang T, et al. Achieving high strength/ductility in bulk $\mathrm{W}-\mathrm{Zr}-\mathrm{Y}_{2} \mathrm{O}_{3}$ alloy plate with hybrid microstructure. Mater Des, 2016, 107: 144-152

22 Zhang Z, Muhammed M. Thermochemical decomposition of cobalt doped ammonium paratungstate precursor. ThermoChim Acta, 2003, 400: 235-245

23 Liu R, Xie ZM, Fang QF, et al. Nanostructured yttria dispersionstrengthened tungsten synthesized by sol-gel method. J Alloys Compd, 2016, 657: 73-80

24 Liu N, Dong Z, Ma Z, et al. Influence of yttrium addition on the reduction property of tungsten oxide prepared via wet chemical method. Acta Metall Sin (Engl Lett), 2020, 33: 275-280

25 Majumdar S, Raveendra S, Samajdar I, et al. Densification and grain growth during isothermal sintering of Mo and mechanically alloyed Mo-TZM. Acta Mater, 2009, 57: 4158-4168

26 Dong Z, Liu N, Ma Z, et al. Synthesis of nanosized composite powders via a wet chemical process for sintering high performance W- $\mathrm{Y}_{2} \mathrm{O}_{3}$ alloy. Int J Refractory Met Hard Mater, 2017, 69: 266-272

27 Dong Z, Liu N, Ma Z, et al. Preparation of ultra-fine grain $\mathrm{W}-\mathrm{Y}_{2} \mathrm{O}_{3}$ alloy by an improved wet chemical method and two-step spark plasma sintering. J Alloys Compd, 2017, 695: 2969-2973

28 Dong Z, Hu W, Ma Z, et al. The synthesis of composite powder precursors via chemical processes for the sintering of oxide dispersion-strengthened alloys. Mater Chem Front, 2019, 3: 19521972

29 Dong Z, Liu N, Hu W, et al. Controlled synthesis of high-quality $\mathrm{W}-\mathrm{Y}_{2} \mathrm{O}_{3}$ composite powder precursor by ascertaining the synthesis mechanism behind the wet chemical method. J Mater Sci Tech,
2020, 36: 118-127

30 Novikov VY. On grain growth in the presence of mobile particles. Acta Mater, 2010, 58: 3326-3331

31 Suwa Y, Saito Y, Onodera H. Phase field simulation of grain growth in three dimensional system containing finely dispersed second-phase particles. Scripta Mater, 2006, 55: 407-410

32 Chang K, Feng W, Chen LQ. Effect of second-phase particle morphology on grain growth kinetics. Acta Mater, 2009, 57: 52295236

33 Delannay F, Missiaen JM. Assessment of solid state and liquid phase sintering models by comparison of isothermal densification kinetics in W and W-Cu systems. Acta Mater, 2016, 106: 22-31

34 Li B, Sun Z, Hou G, et al. The sintering behavior of quasi-spherical tungsten nanopowders. Int J Refractory Met Hard Mater, 2016, 56: $44-50$

35 Kodo M, Soga K, Yoshida H, et al. Doping effect of divalent cations on sintering of polycrystalline yttria. J Eur Ceramic Soc, 2010, 30: 2741-2747

36 Yoshida H, Kodo M, Soga K, et al. Doping effect on sinterability of polycrystalline yttria: From the viewpoint of cation diffusivity. J Eur Ceramic Soc, 2012, 32: 3103-3114

37 Dong Z, Liu N, Hu W, et al. The effect of $\mathrm{Y}_{2} \mathrm{O}_{3}$ on the grain growth and densification of $\mathrm{W}$ matrix during low temperature sintering: Experiments and modelling. Mater Des, 2019, 181: 108080

38 Wang H, Zak Fang Z, Hwang KS. Kinetics of initial coarsening during sintering of nanosized powders. Metall Mat Trans A, 2011, 42: $3534-3542$

39 Srivastav AK, Sankaranarayana M, Murty BS. Initial-stage sintering kinetics of nanocrystalline tungsten. Metall Mat Trans A, 2011, 42: 3863-3866

40 Brook RJ. Controlled grain growth. Treatise Mater Sci Technol, 1976, 9: 331-364

$41 \mathrm{Du}$ ZZ, Cocks ACF. Constitutive models for the sintering of ceramic components-I. Material models. Acta Metall Mater, 1992, 40: 1969-1979

42 Fan D, Chen LQ. Computer simulation of grain growth and Ostwald ripening in alumina-zirconia two-phase composites. J Am Ceramic Soc, 2005, 80: 1773-1780

$43 \mathrm{Hu} \mathrm{W}, \mathrm{Ma} \mathrm{Q}, \mathrm{Ma} \mathrm{Z}$, et al. Ultra-fine $\mathrm{W}-\mathrm{Y}_{2} \mathrm{O}_{3}$ composite powders prepared by an improved chemical co-precipitation method and its interface structure after spark plasma sintering. Tungsten, 2019, 1: $220-228$

44 Liu G, Sun J, Nan CW, et al. Experiment and multiscale modeling of the coupled influence of constituents and precipitates on the ductile fracture of heat-treatable aluminum alloys. Acta Mater, 2005, 53: 3459-3468

45 Liu G, Zhang GJ, Wang RH, et al. Heat treatment-modulated coupling effect of multi-scale second-phase particles on the ductile fracture of aged aluminum alloys. Acta Mater, 2007, 55: 273-284

46 Ritchie RO. The conflicts between strength and toughness. Nat Mater, 2011, 10: 817-822

47 Kumar KS, Van Swygenhoven H, Suresh S. Mechanical behavior of nanocrystalline metals and alloys. Acta Mater, 2003, 51: 57435774

Acknowledgements This work was supported by the National Natural Science Foundation of China (51822404), the Science and Technology Program of Tianjin (19YFZCGX00790 and 18YFZCGX00070), the Natural Science Foundation of Tianjin (18JCYBJC17900) and the Seed Foundation of Tianjin University (2018XRX-0005). 
Author contributions

Dong $\mathrm{Z}$ designed the processing route and experiments and wrote the manuscript; $\mathrm{Ma} Z \mathrm{Z}$ synthesized the materials and implemented the mechanical testing experiments; Yu L carried out the TEM experiments; Liu Y performed the density functional theory calculation. All authors contributed to the discussion, interpretation and presentation of the results.

Conflict of interest The authors declare that they have no conflict of interest.

Supplementary information Experimental details and supporting data are available in the online version of the paper.

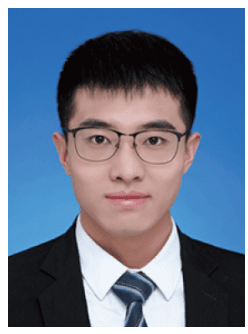

Zhi Dong was born in 1993 in Shanxi Province, China. He acquired his master's degree (in 2017) from the School of Materials Science and Engineering, Tianjin University, China. Since 2018, he has been studying for his $\mathrm{PhD}$ in materials science in Tianjin University. He is currently working on the research into oxide-dispersionstrengthened tungsten alloys, including composite powder fabrication, low-temperature activated sintering and performance test.

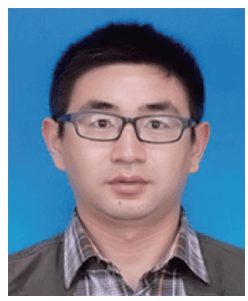

Zongqing Ma was born in 1983 in Shandong Province, China. In 2011, he obtained his $\mathrm{PhD}$ degree in materials science from Tianjin University, China. He is currently a full-time professor at the School of Materials Science and Engineering, Tianjin University, China. He has been doing research on the preparation of highperformance functional/structural materials via powder metallurgy. His interest mainly focuses on the fabrication of composite powders and their sintering characteristics.

\section{通过离子掺杂剂界面偏析来提高氧化物弥散强化 合金的机械性能}

董智, 马宗青 ${ }^{*}$, 余黎明, 刘永长

摘要 氧化物弥散强化铇合金(ODS-W)因具有显著提升的抗辐照 能力、高温强度以及抗蠕变性能而展现出巨大的高温应用潜力. 然而, 分散在合金中的氧化物第二相颗粒容易在铇晶界处团聚并 长大(甚至到微米尺寸), 这大大抑制了它们对铇合金的强化效果.

目前, 如何有效细化和分散铇晶界处的氧化物第二相颗粒一直是 人们面临的巨大挑战. 在本文中, 我们通过共沉积湿化学法和后续 低温烧结成功制备出一种新型的离子掺杂的氧化钇弥散强化铇合 金. 结果发现, 合适的离子掺杂不仅可以显著细化晶界处的氧化钎 颗粒, 而且可以改善铇基体的烧结特性. 这些掺杂效应最终同时提 高了铇合金的强度和韧性. 经过分析可以确认离子掺杂剂在铇/氧 化钎界面处的偏析是这些掺杂效应的起源. 此外, 经X射线光电子 发射光谱(XPS)表征发现, 离子掺杂剂偏析能显著改变铇/氧化钇界 面的化学键合状态(即 $\mathrm{W}-\mathrm{O}$ 键), 进而使控制 $\mathrm{W}$ 晶粒生长的表面扩散 机制也受到影响, 这很好地解释了不同离子掺杂的铇合金中产生 的晶粒尺寸差异. 至于铇晶界处氧化钇的细化, 可以从动力学和热 力学的角度来解释. 在热力学方面, 铇/氧化钎界面能降低了氧化钎 粒子长大的驱动力. 在动力学方面, 离子掺杂剂的界面偏析降低了 氧化钇分子的移动能力. 更重要的是, 离子掺杂的方法也能应用于 其他的氧化物弥散强化合金来提高他们的综合力学性能. 